\title{
La construcción del Capitolio de La Habana
}

\section{The construction of the Havana Capitol}

\author{
$\underline{\text { M. Mestre Martí }}{ }^{(*)}$, P.M. Jiménez Vicario ${ }^{(*)}$, M.A. Ródenas-López ${ }^{(*)}$
}

\section{RESUMEN}

Este año (2019), la Oficina del Historiador de la Ciudad de La Habana ha finalizado la restauración del Capitolio Nacional de Cuba. Este artículo describe los métodos constructivos utilizados en su ejecución, entre 1926 y 1929, poniendo énfasis en las proezas que lograron finalizar la obra en un plazo de ejecución brevísimo para las condiciones y técnicas del momento: tan solo tres años. Ello ha sido posible gracias a un proyecto de cooperación internacional subvencionado por la Universidad de Alicante, que permitió varias estancias de investigación allí. Se consultaron las pocas publicaciones históricas que existen en los archivos cubanos, así como los escritos y planos originales del Capitolio, realizados a mano, y se realizaron múltiples visitas in situ, para elaborar un análisis del estado de conservación de la obra y del método constructivo empleado, que ha permitido conocer y valorar mejor la obra y facilitar el proceso de intervención arquitectónica.

Palabras clave: Capitolio de La Habana, arquitectura cubana, construcción.

\section{ABSTRACT}

This year (2019) the Havana City Historian's Office has completed the restoration of the National Capitol. This paper highlights the constructive methods used in its execution (between 1926 and 1929) emphasizing the feats that managed to finish the work in a very short time for the conditions and techniques of the moment: only three years. This has been possible thanks to an international cooperation project subsidized by the University of Alicante, which allowed several research stays there. The few historical publications that exist in the Cuban archives were consulted, as well as the writings and original plans of the Capitol, drawn by hand, and multiple visits were made in situ, in order to elaborate a work's analysis of its state of conservation and the used constructive method, that has allowed to better know and value the work and to facilitate the process of the architectural intervention.

Keywords: The Havana Capitol, Cuban architecture, construction.

(*) Departamento de Arquitectura y Tecnología de la Edificación, Universidad Politécnica de Cartagena (España). Persona de contacto/Corresponding author: maria.mestre@upct.es (M. Mestre Martí)

ORCID: https://orcid.org/oooo-0002-5249-8643 (M. Mestre Martí); https://orcid.org/oooo-0002-8687-7051 (P.M. Jiménez Vicario); https://orcid.org/oooo-0002-7485-117X (M.A. Ródenas López)

Cómo citar este artículo/Citation: Mestre Martí, M.; Jiménez Vicario, P.M.; Ródenas López, M.A. (2019). La construcción del Capitolio de La Habana. Informes de la Construcción, 71(556): e319. https://doi.org/10.3989/ic.66826

Copyright: (C) 2019 CSIC. Este es un artículo de acceso abierto distribuido bajo los términos de la licencia de uso y distribución Creative Commons Reconocimiento 4.0 Internacional (CC BY 4.0). 


\section{INTRODUCCIÓN Y OBJETIVOS}

El pasado 1 de marzo del 2018 se abrió al público el primer recorrido interior por el Capitolio Nacional de Cuba. La intervención arquitectónica en este emblema patrimonial es, hasta ahora, el mayor proyecto de restauración al que se ha enfrentado la isla, por su tamaño, envergadura y también por su estado de conservación. Se ha tratado de cumplir con el objetivo de que los trabajos de restauración, comenzados en 2010, estén finalizados antes de la celebración del 500 aniversario de la fundación de La Habana. Para que en esa fecha, noviembre del 2019, las lámparas de la linterna de la cúpula iluminasen de nuevo la ciudad.

Desde su inicio, el Capitolio de la Habana fue un referente histórico en la trama de la capital contemporánea de Cuba tanto por sus dimensiones $\left(43.600 \mathrm{~m}^{2}\right.$ de solar, $13.483,3 \mathrm{~m}^{2}$ de edificación y 26.391,69m² de parques y jardines) como por su monumentalidad, representatividad y alto simbolismo social y político ${ }^{1}$. (Figura 1)

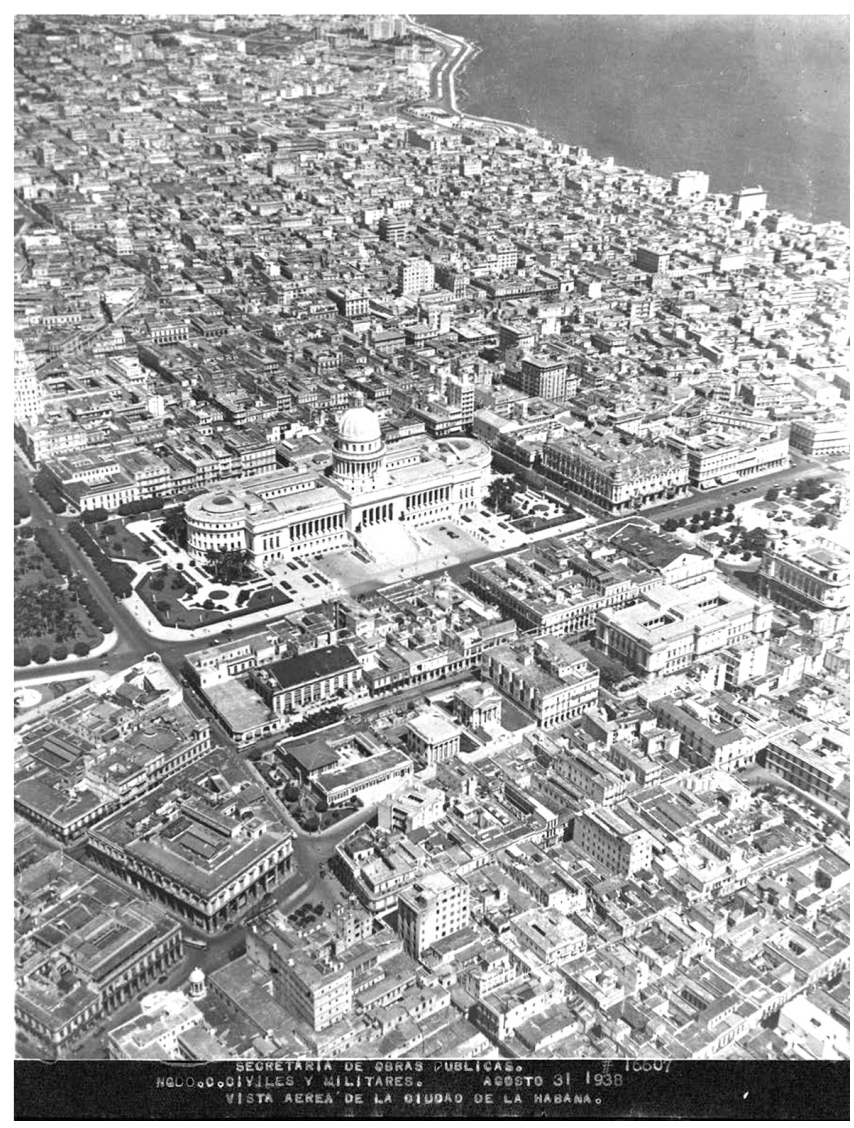

Figura 1. Vista aérea del frente del Capitolio, 31 Agosto, 1938 Fuente: Archivo Secretaría de Obras Públicas. Negociado de Construcciones Civiles y Militares.
A pesar de la importancia de tan emblemático edificio, son escasas las publicaciones históricas que hay sobre él ${ }^{2}(1)$, por lo que se desconocen los métodos constructivos que permitieron cumplir con los breves plazos de ejecución que se habían programado. Este es el objeto de este artículo. En apenas tres años se coordinó de forma precisa a unos 8.00o trabajadores especializados (Figura 2) y se emplearon los medios más avanzados para la época, fruto de la participación estadounidense en la parte técnica. Las obras del Capitolio comenzaron el 1 de abril de 1926 y en mayo de 1929 el edificio estaba prácticamente terminado.

\section{“(...) centenares de obreros se movían en todas direccio- nes; cuantos medios mecánicos modernos son conocidos fueron empleados en persecución del ideal y todo se eje- cutaba cronométricamente, con un orden y organiza- ción tal, que semejaba un pequeño ejército que acciona- ba a la voz de mando de su Jefe." (1)}

Este artículo es fruto de la investigación nacida en el seno de la cooperación entre la Universidad de Alicante (UA) y la Oficina del Historiador de la Ciudad de La Habana $(\mathrm{OHCH})$ que permitió desarrollar una estancia de investigación a varios de los miembros del grupo de investigación Aedificatio a través del Proyecto Habana ${ }^{3}$, financiado por la Subdirección de Cooperación Universitaria al Desarrollo de la UA, cuyo fin fue la elaboración de un informe general del estado de conservación de la obra que sirviera para el equipo de trabajo de Diagnóstico de la $\mathrm{OHCH}$ en los preparatorios de su intervención que comenzó en el mismo año 2011. A su vez, se desarrolló una estancia posdoctoral en La Habana de un año gracias a la Fundación Española para la Ciencia y la Tecnología (FECYT) de una de las autoras de este artículo.

\section{METODOLOGÍA}

La información relativa al proceso constructivo se ha obtenido consultando las pocas copias de publicaciones históricas que hay sobre él, siendo solo posible examinarlas físicamente en los archivos de la Habana. Simultáneamente se tuvo acceso a la documentación gráfica y fotográfica existente en el archivo del Capitolio: fotografías de la época y planos que no han visto la luz hasta la fecha (Figura 3). También a través de frecuentes visitas in situ, organizadas en colaboración con la $\mathrm{OHCH}$, el edificio se fue estudiando cuando éste aún estaba cerrado al público, pudiendo acceder tanto a las partes públicas como al interior de la cúpula o a los sótanos, no visitables.

Además de los planos y fotografías, el propio edificio narra su historia en detalles ornamentales como los bajorrelieves. Éstos describen la historia general de Cuba y el desarrollo de la construcción del propio edificio. Se trata, por tanto, de

\footnotetext{
Como dato que atestigua esta significación, es importante conocer que el área declarada Patrimonio de la Humanidad en 1981 fue ampliada en 2016, abarcando la totalidad de los terrenos del Capitolio Nacional, además del Palacio de Aldama y su entorno. World Heritage Centre. UNESCO. Decision: 40 COM 8D. Clarifications of property boundaries and areas by States Parties. 2016.

2 Salvo El Libro del Capitolio, escrito en 1933 por P. Fernández y Cía., editado en la época de su construcción, existen tan solo unos pocos ejemplares, en la isla de Cuba. Contiene una descripción detallada de la historia de su construcción desde que el solar donde se edificó era tan solo una ciénaga hasta su inauguración. De él se ha extraído parte de la historia del emplazamiento, así como algunos datos para el análisis constructivo y las fotografías. Este libro describe con bastante detalle la estructura que sostiene este edificio, aunque de manera compleja, por lo que el presente trabajo pretende dar una visión clara y global de sus soluciones constructivas.

3 Proyecto Habana constituye una estrategia de internacionalización, investigación y educación para estudiantes universitarios aplicada a la Conservación del Patrimonio Cubano y a su puesta en valor.
} 


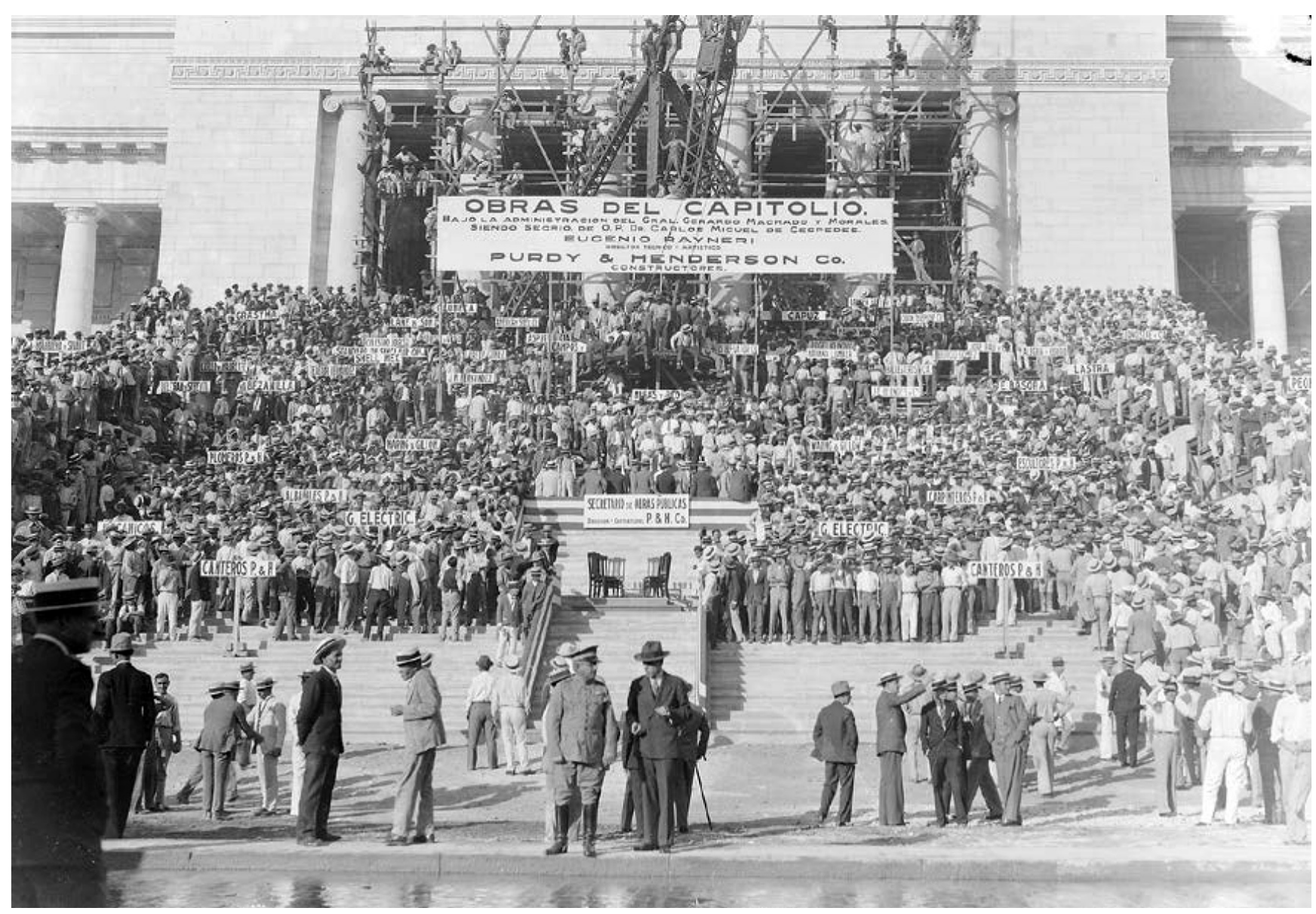

Figura 2. El General Gerardo Machado con los trabajadores del Capitolio, 1929. Fuente; Archivo Secretaría de Obras Públicas. Negociado de Construcciones Civiles y Militares, 1929.

información histórica complementaria que convierten al elemento constructivo en un documento de lectura histórica que singulariza la obra monumental.

Todo ello permitió realizar un levantamiento complementario de los planos del edificio y completar un estudio de su estado de conservación. El contenido de este artículo forma parte de una primera fase de estudio centrada en el estudio histórico y constructivo del edificio, en el análisis general del estado de conservación del edificio y en las patologías del cuerpo central del edificio.

\section{EL CAPITOLIO DE LA HABANA}

\subsection{El emplazamiento}

Durante el primer tercio del siglo XIX, el solar donde se encuentra el Capitolio Nacional fue una gran ciénaga-vertedero extramuros, en el que se acumulaban las basuras de la Habana Vieja. Años más tarde, gracias al esfuerzo de la Sociedad Económica de Amigos del País, el terreno fue saneado, permitiendo que entre 1817 y 1831 se instaurara el primer centro de estudios botánicos de la ciudad. En 1831 los terrenos fueron expropiados para construir el Camino de Hierro que uniría La Habana con Villa de Güines, completado en 1838. La concesión recayó sobre el Conde de Villanueva, Presidente del Consejo Directivo del Ferrocarril, en cuyo honor se nombró Estación de Villanueva al para- dero construido en las inmediaciones del futuro Capitolio (Figura 4).

Este dato es importante ya que la proximidad de la vía ferroviaria fue uno de los hechos que motivaron la corta ejecución de las obras del Capitolio. El otro fue el compromiso adquirido de celebrar la Sexta Conferencia Panamericana en el edificio del Capitolio, programada para enero de 1928.

El crecimiento poblacional de Cuba desde la Guerra de la Independencia (1898) (2) evidenció la necesidad de construir una nueva y moderna estación de ferrocarril. En 1910, los terrenos de la Estación de Villanueva fueron canjeados por los del antiguo Arsenal, comprendidos entre los Almacenes de San José, el Arsenal, ocupado por The Havana Central Railway Co., la línea de costa y la calle de Factoría, trasladando la estación término allí. Los terrenos quedaron libres y, tras haberse derribado las murallas de la ciudad a partir de 1863 , se hallaban ubicados en un área estratégica que ahora pasaría a ser central, entre el núcleo histórico original y la expansión de la ciudad, hacia el Norte.

En la actualidad el Capitolio de la Habana no solo es un emblema histórico y patrimonial sino que posee un valor urbano añadido como elemento vertebrador de la ciudad contemporánea, a modo de rótula entre el centro histórico La Habana Vieja y el barrio Centro Habana, además de formar parte del eje del Paseo del Prado. 


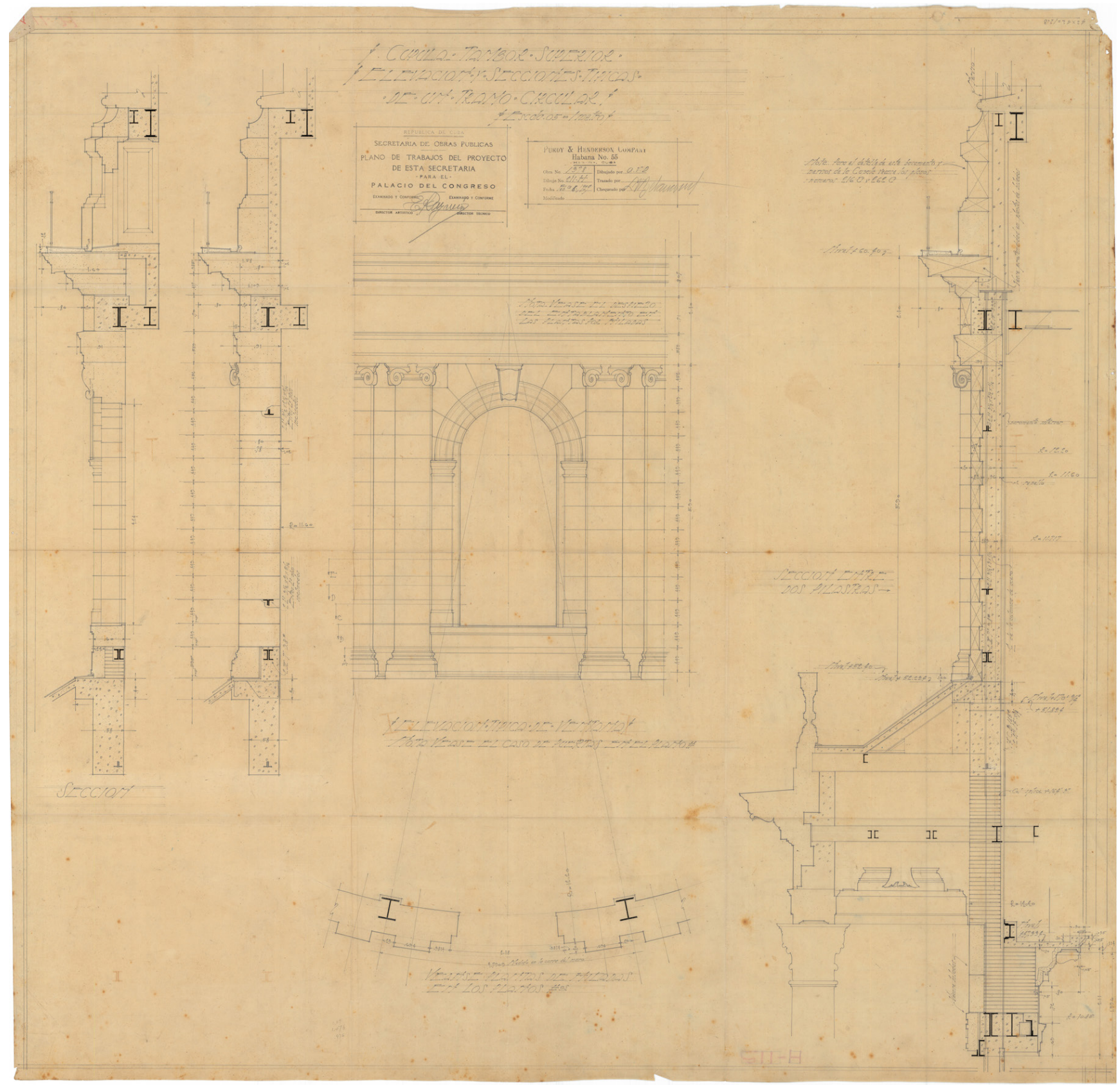

Figura 3. Plano núm. 211.77. Cúpula Tambor Superior. Elevación y sección típicas de un tramo circular. 6 de febrero 1929. Por la parte cubana, firmado por el Arq. Eugenio Raynieri y por la parte neoyorquina (Purdy and Herderson)

\subsection{Del concurso internacional al proyecto definitivo: un camino lleno de vicisitudes}

Al concurso internacional que se convocó en 1911 para la construcción del Palacio Presidencial en estos terrenos se presentaron 21 proyectos, 17 de los cuales no cumplían con las bases establecidas (1). De entre los cuatro proyectos seleccionados (León de Oro, Demon, La República y Estrella Solitaria) salió elegido "La República”, obra de los arquitectos cubanos Eugenio Rayneri Sorrentino y Eugenio Rayneri Piedra (padre e hijo).

Los primeros trabajos para la ejecución del Palacio Presidencial quedaron suspendidos en 1913 al ocupar la Presidencia de la República el General Mario García Menorcal. Los arquitectos cubanos Mario Romañacha y Félix Cabarrocas fue- ron designados por el Negociado de Construcciones Civiles y Militares para la adaptación de los planos. Cabarrocas, encargado de las plantas y fachadas transformó el proyecto original adicionándole dos hemiciclos, el de la Cámara de Representantes y el del Senado, modificó la cúpula y las bóvedas y transformó también el vestíbulo y las escaleras principales. (1)

En 1925, siendo presidente el General Gerardo Machado y Morales (1925-1933), se ordenó el desalojo de los terrenos del Capitolio (ocupados por ferias y mercados desde la Primera Guerra Mundial) y se planteó el estudio de un nuevo proyecto de Capitolio a Evelio Govantes y Félix Cabarrocas. Partiendo de lo que ya estaba ejecutado, éstos introdujeron nuevas modificaciones que conformarían la base del que ahora es el Capitolio Nacional. La fecha de entrega estaba condicionada 


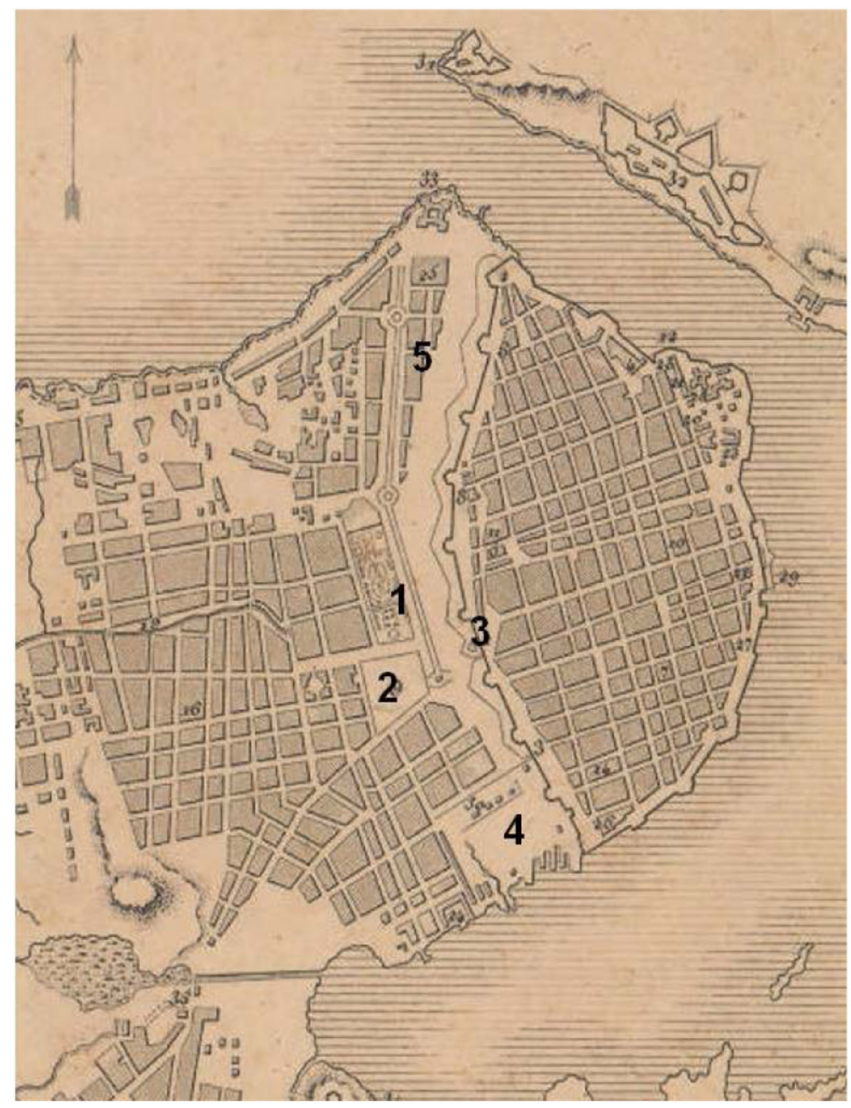

Figura 4. Evolución del emplazamiento del Capitolio de la Habana 1817: 1.- Jardín Botánico; 2.- Campo de Prácticas del Ejército; 3.- Puerta de Tierra de la Muralla.

1834: 1.- Estación de Ferrocarril; 2.- Campo de Marte; 4.- El Arsenal.

1910: 1.- Palacio Presidencial; 4.- Estación Ferrocarril.

1912: 1.- Capitolio; 2.- Plaza de la Fraternidad; 5.- Nuevo Palacio Presidencial.

a la Sexta Conferencia Internacional Americana prevista en el mes de enero de 1928. Siendo consecuentes con ello, el 22 de febrero de 1926 se adjudicaron por subasta las obras a la constructora neoyorquina Purdy and Henderson Company, establecida en La Habana desde principios del siglo XX Ya antes la compañía se había pronunciado afirmando lo siguiente:

"La firma Purdy and Henderson Company se compromete a comenzar la construcción del Capitolio dentro de una semana y a trabajar día y noche si fuere necesario, a fin de entregarlo terminado, decorado y amueblado, listo para ser ocupado, en Diciembre de 1927 [...] de acuerdo con los planos principales ya preparados o terminándolos y modificándolos a medida que las obras se vayan realizando; a hacer y someter a la aprobación del señor Secretario de Obras Públicas los modelos $y$ detalles que se requieran y a utilizar los ingenieros, arquitectos y artistas que sean necesarios, cediendo gratuitamente el uso de toda su planta de fabricación, consistente en mezcladoras de concreto, torres de acero, grúas, bombas, máquinas, sierras, etc.”(1)
Eran conscientes que las dificultades nacían del propio proyecto ejecutado con anterioridad y el proyecto de ejecución que se encontraba a medio redactar. Ellos eran los únicos, o al menos así se refería la compañía en garantizar "que los problemas que para otros casos parezcan insolubles no lo serán para nosotros, si se nos adjudica la subasta y se sigue a nuestras indicaciones en la ejecución de la obra”. (1)

El porqué de esta afirmación tiene que ver con el tiempo que la compañía llevaba trabajando en la cuestión, a pesar de no haberse celebrado la adjudicación de la misma, concretamente desde antes del 5 de diciembre de 1925, según lo atestigua el presidente de la compañía tras la selección por parte del Tribunal de la Subasta (1). Su acercamiento se centró en preparar la "vastísima organización". Una de las primeras decisiones fue prever la escasez de tierra dura, materiales y mano de obra para cortar la piedra de Capellanías de las extensas fachadas del Palacio del Congreso, para lo cual indicaron a las canteras de Capellanías ${ }^{4}$, primeramente, y a las de Cazadores y San José, en segundo lugar, la necesidad de aumentar su maquinaria de extracción. También empezaron a preparar la contratación de canteros residentes en Cuba y establecieron contacto con agentes españoles y con los grandes centros vendedores de mármol. Al mismo tiempo, ordenaron a sus ingenieros y dibujantes hacer los primeros cálculos y estudiar posibles detalles.

Finalmente las obras comenzaron en abril de 1926 y aunque se trató de aprovechar en la medida de lo posible la edificación que ya se había ejecutado del antiguo proyecto, ésta tuvo que ser prácticamente rehecha debido a los graves defectos arquitectónicos que presentaba. Desde la Secretaría de Obras Públicas cubana se designó a Raúl Otero como Director Artístico, encargado de la confección de los planos generales de la obra y responsable del aspecto estético de ésta, y a Eugenio Rayneri Piedra como Director Técnico, encargado de la organización de los trabajos y responsable de la solidez de la construcción y de la economía en general de los procedimientos. Por último, se eligieron a los Ingenieros Enrique Merry y José Sabí Carreras, por parte de la constructora neoyorquina.

Pero la labor de Raúl Otero fue breve debido a otros requerimientos laborales por parte de la Secretaría de Obras Públicas de Cuba. Le sustituyó José M. Bens Arrarte, arquitecto cubano, quien durante la ejecución de la obra introdujo varias modificaciones y realizó estudios de plantas, alzados, alturas y estudios preliminares de la cúpula (3) ${ }^{5}$. Además, ordenó algunas demoliciones ya ejecutadas y se encargó de enlazar las obras ejecutadas con las proyectadas.

Finalmente renunció al cargo por la imposibilidad de terminar las obras en el plazo establecido, los continuos cambios de materiales y costos debido a la gran cantidad de obras ejecutadas sin estar previstas y la gran cantidad de planos sin finalizar. Su puesto fue asumido por el ya entonces Director Técnico, Eugenio Rayneri, en una importante reestructuración dirigida por el Secretario para volver a estar en condiciones de cumplir los plazos, que incluía prescindir del personal y enseres dedicados a la confección de maquetas y la fusión de dibujantes de los contratistas con el Departamento de Obras Públicas.

\footnotetext{
4 Las canteras de Capellanías se encuentran situadas entre Ceiba del Agua y Artemisa, en la provincia de Pinar del Río.

5 En el artículo Mestre Martí (2018) se pueden apreciar las proporciones generales y el esquema compositivo en planta.
} 


\subsection{Metodología de trabajo con un objetivo: cumplir con los plazos de ejecución}

Se establecieron tres estrategias para ganar tiempo. La primera fue ralentizar la marcha de los trabajos para poder dibujar los planos de ejecución que a largo plazo podrían garantizar la resolución de los problemas que se fueran encontrando y así evitar nuevos retrasos. Rayneri y su equipo de dibujantes desarrollaron en un corto espacio de tiempo las soluciones para los problemas pendientes y la finalización del proyecto arquitectónico, afrontando los estudios definitivos de elementos tan significativos como los Hemiciclos del Senado y la Cámara que aún se encontraban en estado de boceto. Se dibujaron los planos de carpinterías, revestimientos y decoración que fueron utilizados por las distintas empresas decoradoras. Se contrató además a la oficina neoyorkina de Purdy and Henderson Co. para el diseño y cálculo de la estructura y cimentación de la cúpula a partir de unos planos generales bastante indefinidos.

A pesar de los esfuerzos, el plazo de entrega se retrasó finalmente hasta el 20 de mayo de 1928 para lo cual el Secretario informaba de la necesidad de adquirir más equipos para el corte de cantería, de ordenar la construcción de una torre de acero para la construcción de la cúpula, de contar con libertad para contratar con firmas solventes y responsables y fondos suficientes en todo momento ${ }^{6}$. En estas condiciones se puso en marcha la segunda estrategia que consistió en invertir una importante cantidad de dinero para equiparar la velocidad de la obra con los nuevos planos. Se construyeron las estructuras de acero de las cubiertas del Hemiciclo del Senado y la Cámara y varios techos y cubiertas que se encontraban aún sin ejecutar. De este modo, a excepción de la cúpula, el edificio quedaba listo para la decoración y para los revestimientos de acabado.

La tercera estrategia derivada de las anteriores fue solapar los distintos oficios y fases de la obra. Así, se ejecutaron al mismo tiempo aparejos de ladrillo y estructuras de hormigón y acero. Algunas de las empresas de decoración colaboraron en el diseño haciendo sus propias creaciones. Fue el caso de la firma inglesa Waring and Guillow Ltd. que se encargó de diseñar, a partir de los planos y detalles definitivos, las salas de Conferencias, los despachos de los Presidentes del Senado y la Cámara y Comités Parlamentarios ${ }^{7}$. A su vez Waring and Guillow Ltd. subcontrató muchos trabajos a empresas y artesanos locales, siempre bajo la supervisión de Eugenio Rayneri y Purdy and Henderson Co. Los trabajos para la colocación del mármol se le encargaron a la firma italiana Fratelli Remuzzi ${ }^{8}$ (4) y la alemana Vereinigte Fichterlgebirge-Granit Syenit u Mamorwerke A.G.

A comienzos de 1928 trabajaban bajo la organización de Purdy and Henderson Co. más de cuarenta subcontratistas con su propio personal.

\subsection{Sistemas constructivos}

\section{Excavaciones y cimentación}

La cimentación supuso un importante contratiempo para el desarrollo de las obras en los plazos establecidos. El primer inconveniente era las condiciones del propio solar con un terreno colmatado de escombros. El segundo era el desconocimiento del valor de la resistencia del terreno para los nuevos cálculos. El tercer y más importante era la existencia de cimientos ya ejecutados según el anterior proyecto, cuyos trazados no coincidían con la nueva estructura o si coincidían eran difícilmente adaptables para soportar las nuevas cargas. Las dos primeras dificultades se solventaron excavando hasta una profundidad mayor para encontrar el terreno firme (en los casos más críticos hasta 7 metros) teniendo que achicar el agua procedente de filtraciones y del drenaje natural del terreno con sifones de vapor. Como base para los cálculos se estimó que la resistencia del terreno era de 3 toneladas por pie cuadrado $\left(32,25 \mathrm{~T} / \mathrm{m}^{2}\right)$ teniendo como referencia las edificaciones vecinas que Purdy and Henderson había realizado ${ }^{9}$ (El Hotel Plaza, el Centro Asturiano, el Centro Gallego, el Hotel Inglaterra y el Diario de la Marina).

En cuanto al tercer inconveniente se comprobó que parte de los macizos de hormigón ejecutados para la cimentación previa no podía destruirse con la grúa excavadora, por lo que se decidió aprovecharlos para no retrasar las obras. Se presentaba el inconveniente de que los ejes previos no coincidían con los nuevos y que las secciones eran insuficientes para el nuevo edificio. Era preciso por tanto reforzarlos. Este fue el caso de la cimentación de la fachada posterior, que alberga la biblioteca del Congreso. Este cuerpo central estaba previsto que tuviera una sola altura, pero para que adquiriera mayor amplitud en los pisos superiores, se modificó en proyecto, alcanzando la altura total del edificio. En las secciones de concentración de cargas se construyeron contrafuertes que abrazaban la cimentación anterior y soportaban una viga de atado de hormigón armado que colaboraba en adquirir la sección de hormigón necesaria y que se disponía a lo largo de todo el muro de carga. Para absorber la excentricidad de las cargas, se añadió una nueva cimentación exterior en forma de zapata corrida de hormigón reforzado que se anclaba a la existente.

En la parte exterior del edificio, se utilizaron zapatas corridas bajo los muros de carga y bajo los pilares de hormigón de la parte central de la fachada. En el centro de los hemiciclos se emplearon zapatas aisladas y encepados bajo los pilares intermedios y pilotes de madera de jiquí en los asientos de la cúpula (Figura 5).

Encontramos cimentaciones de hormigón reforzado de espesores variables con refuerzos de acero corrugado en su base, espaciados de forma uniforme. Muchas de ellas presentaban excentricidades con los ejes de pilares o muros al recibir cargas excéntricas. Debido a las grandes secciones de pilares y

\footnotetext{
${ }^{6}$ En marzo de 1927, el Secretario reunió a Eugenio Rayneri y a dos representantes de Purdy and Henderson Co. con el objetivo de saber los requerimientos para terminar el Capitolio el 20 de mayo de 1928 y el costo de los mismos.

7 Para ello se les cedió unos antiguos almacenes de carga de ferrocarril donde instalaron sus oficinas y talleres.

8 "Los trabajos en mármoles comprendieron: $8.000 \mathrm{~m}^{2}$ de pisos; $2.000 \mathrm{~m}^{2}$ de escaleras con sus vestiduras laterales; 1.000 m² de zócalos; $300 \mathrm{~m}^{3}$ de trabajos escultóricos y artísticos ejecutados en ónix y 106 pilastras macizas de 9 metros de altura que consumieron unos 400 m ${ }^{3}$ de mármol verde". (De Las Cuevas, T., 2001, p. 259).

9 Sí que se hicieron catas en una fase posterior de la construcción, previamente a los cálculos de la estructura de la cúpula.
} 


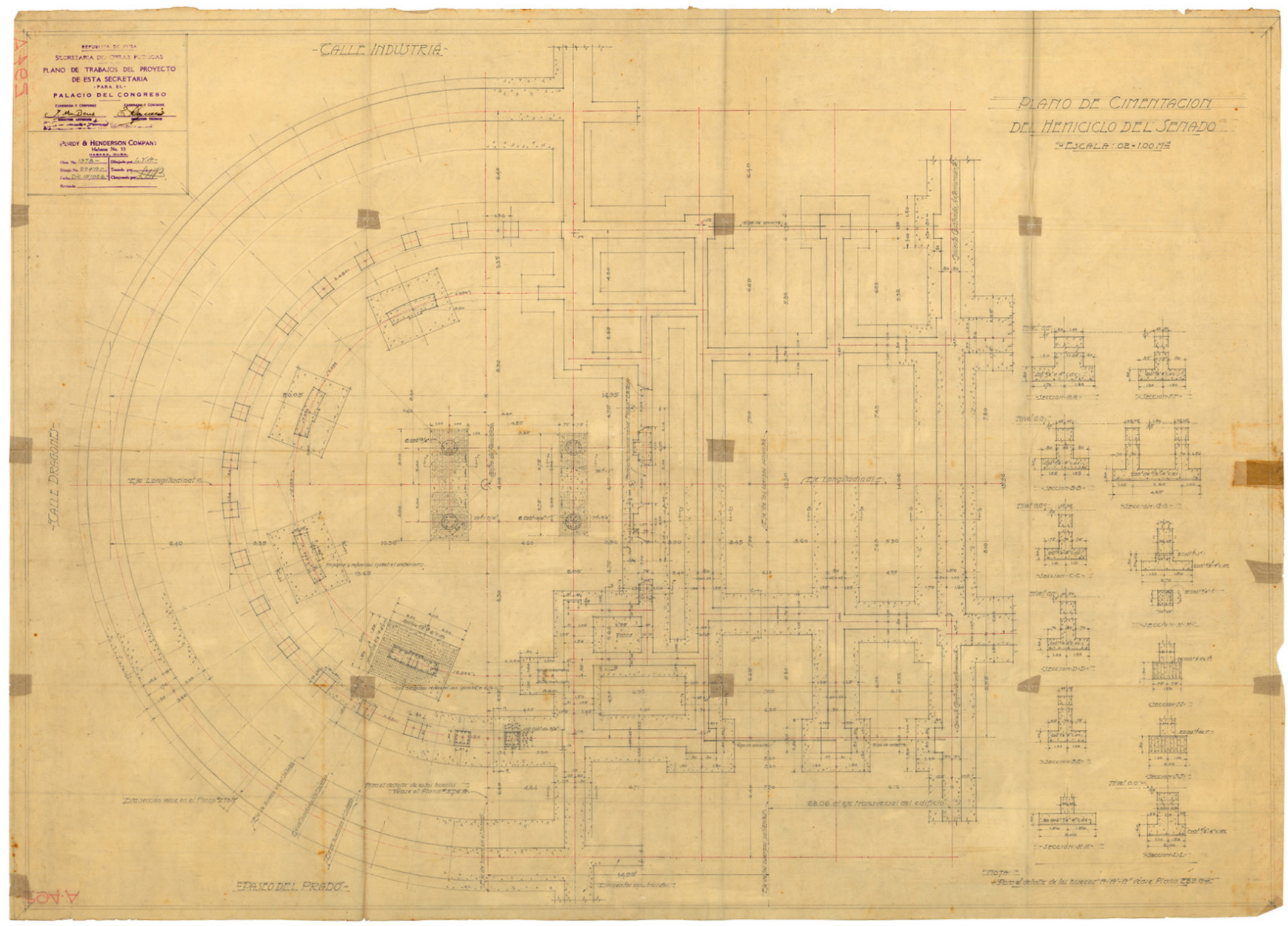

Figura 5. Plano de cimentación del Hemiciclo del Senado. Dib. Núm.: 294. A. 15 dic 1926. Dibujado por L.Y.A. (Purdy and Herderson). Supervisado por E. Raynieri y José M. Bens Arrarte, (director artístico).

muros, la cimentación en muchas zonas superaba los $2 \mathrm{~m}$ de ancho y $5 \mathrm{~m}$ de profundidad. En aquellas donde no había concentración de cargas se ejecutaron losas con hormigón y piedra, evitando el uso del acero como refuerzo y economizando de este modo en función de las cargas.

Terminada la cimentación y habiendo superado las dificultades que ésta había generado, los contratistas enviaron una comunicación al Secretariado de Obras Públicas informando de los retrasos por los contratiempos y los desembolsos extraordinarios originados. Su intención era poner en cuestión la finalización de la obra en las fechas pactadas y pedir la correspondiente prórroga. El Secretariado de Obras Públicas no accedió a la demanda apercibiéndolos de las responsabilidades en las que incurrirían.

\subsection{Estructura portante}

Materiales empleados

Los materiales empleados en la estructura responden por un lado a la tradición constructiva (materiales pétreos y reves- timientos convencionales) y por otro a la vanguardia de la época (materiales novedosos y poco explorados como el hormigón armado, el hormigón reforzado y el acero). Si bien los materiales tradicionales ofrecían las garantías de durabilidad que la experiencia arrojaba, los nuevos materiales y sistemas dibujaban un panorama con serias dudas sobre la idoneidad en un ambiente salino y húmedo, con fuertes temporales. ${ }^{10}$

La piedra se empleó en los muros de carga y columnas. El muro de la planta baja constituye un basamento sobre el que se asienta el edificio en toda su longitud, únicamente interrumpido por la escalinata principal, de granito. Para su construcción se tuvo en cuenta el espesor máximo de los bloques de piedra de Capellanía obtenibles de las canteras ${ }^{11}$ de la calidad requerida, que en algunos casos superaban los 10" $(25,4 \mathrm{~cm})$, logrando contar con piezas del espesor completo del muro. Por ello, tras su nivelado y aplomado, en muy pocas ocasiones hubo que recurrir al empleo de piezas de anclaje o trabado.

El resto de soportes del edificio son en su mayoría de hormigón armado, excepto en la zona de la cúpula, que son de acero

${ }^{10}$ Las patologías detectadas en el edificio afectan principalmente a revestimientos y desprendimiento de hormigón como consecuencia de la oxidación de los elementos metálicos en forjados y vigas debido a un espesor insuficiente de mismo.

${ }^{11}$ De las canteras, situadas entre Ceiba del Agua y Artemisa, en la provincia de Pinar del Río. La piedra de Capellanías pertenece al grupo de las calizas bastas, aunque presenta vetas de cuarzo. 


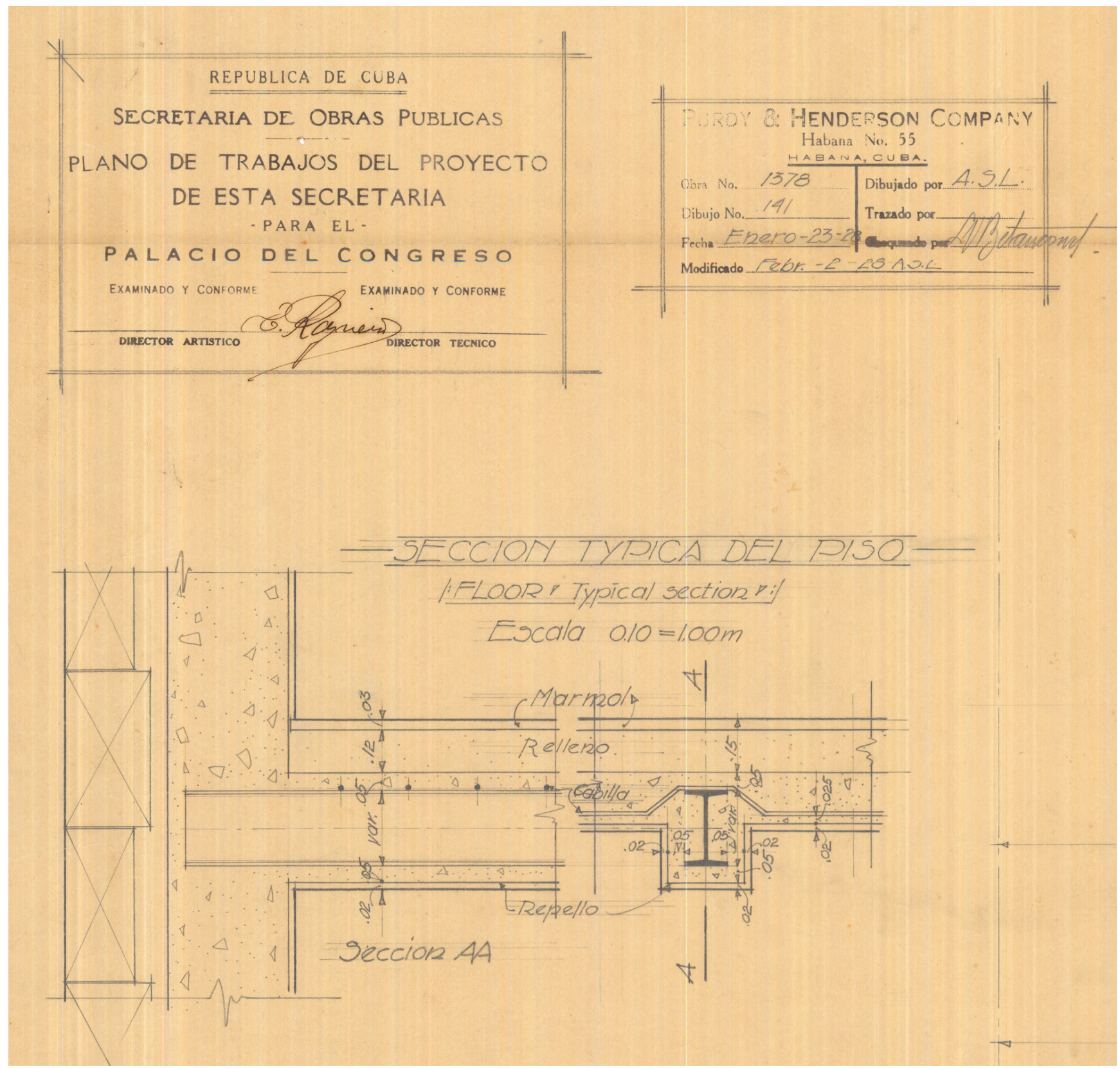

Figura 6. Detalle tipo de forjado. Dib. Núm.: 141. 02 feb 1928. Dibujado por A.S.L. (Purdy and Herderson). Supervisado por E. Raynieri y José M. Bens Arrarte, (director artístico).

estructural. Los forjados se resolvieron con losas de hormigón armado que apoyan sobre vigas de acero revestidas de hormigón (Figura 6).

Por la complejidad espacial del edificio y de su decoración, se optó por emplear vigas de diseño específico, en vez de piezas normalizadas. Por ejemplo, en el Salón de los Pasos Perdidos se emplearon grandes vigas de acero sobre pilares de hormigón ${ }^{12}$, que no hubieran resistido los esfuerzos cortantes transmitidos por éstas si no se hubieran reducido los empujes laterales al máximo al ser de alma llena. La fabricación de cada una de las vigas fue compleja, ya que para conseguir la geometría curva debían unirse distintas piezas de angulares y perfiles, taladradas independientemente y armadas después en conjunto (Figura 7) (5). Estas vigas prefabricadas se colocaron mediante una grúa que redujo los tiempos de colocación facilitando el proceso.

Dado el tamaño del edificio y su complejidad se recurrió a una gran variedad de soluciones constructivas que exponemos a continuación y que nos interesa destacar por su singularidad o relevancia. Las analizamos según su localización (Figura 8):

Fachada posterior-volumen central

La bóveda de la cubierta de la 'Porte Cochera' de la fachada posterior se proyectó inicialmente de hormigón macizo para cubrir un espacio de $2 \mathrm{~m}$. de ancho, $12 \mathrm{~m}$. de largo y más de

\footnotetext{
${ }^{12}$ Se construyeron pilares de hormigón reforzado de 48 pies $(14,63 \mathrm{~m})$ de luz libre sobre las que apoyan 18 vigas de 30 ” de canto (76,2 cm) reforzadas con en sus dos alas.
} 


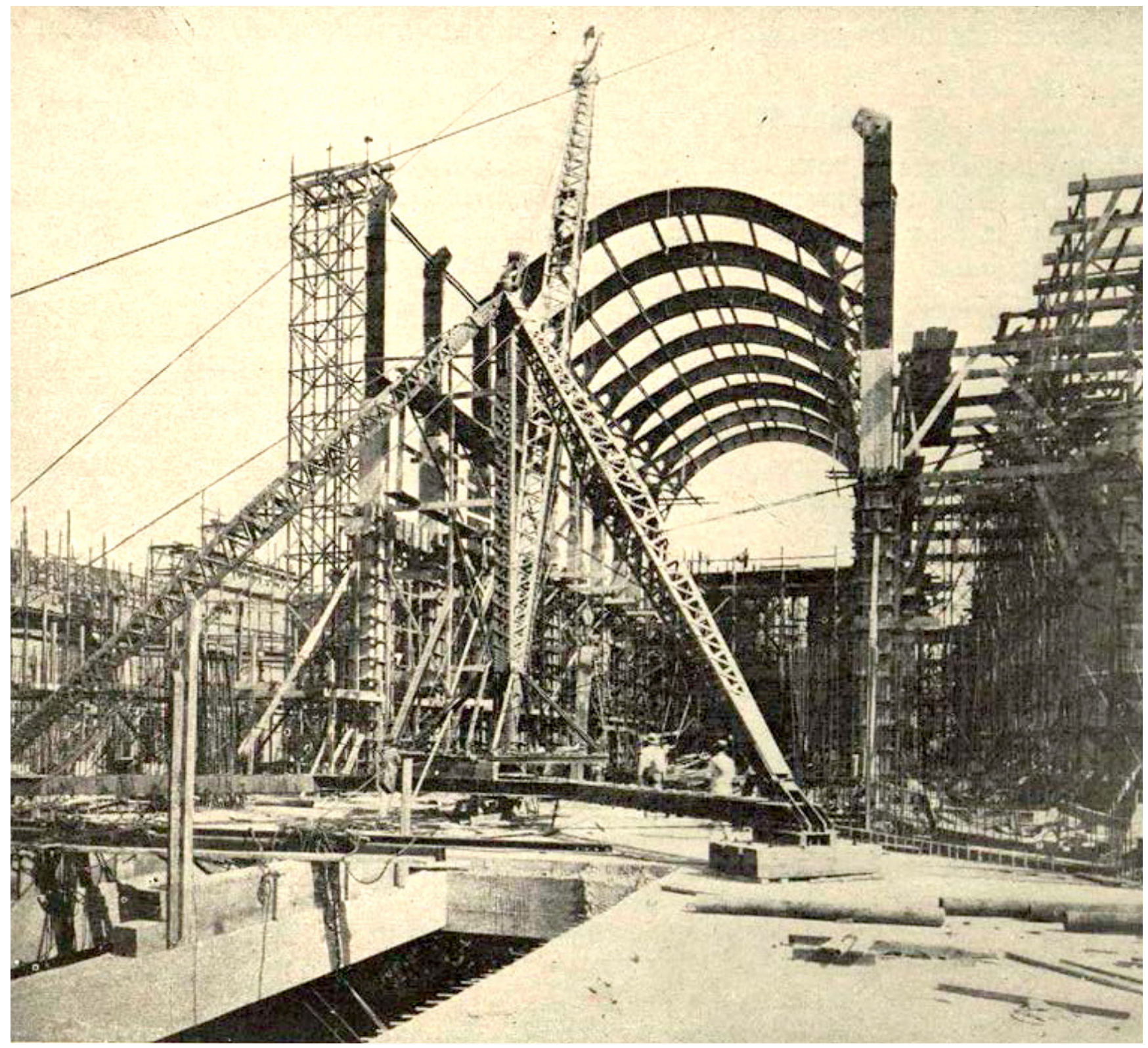

Figura 7. Estructura del Salón de los Pasos Perdidos. Fuente: Revista El Arquitecto. Imágenes extraídas del nº 38. "El Capitolio visto por un Arquitecto", publicada en 1933. (5)

$4 \mathrm{~m}$. de altura. Debido a la negativa de la dirección técnica y artística de variar el proyecto, se le propuso al mínimo el volumen de hormigón, obteniendo la resistencia necesaria y disminuyendo considerablemente el peso. La propuesta, que fue aceptada, consistía en una estructura formada por 4 arquitrabes formados por vigas metálicas de las que colgaba la bóveda mediante tensores hechos con dos angulares que generaban un apoyo con perfiles metálicos en todo el desarrollo longitudinal de la base de la bóveda y que a su vez se empotraban en el muro mediante vigas. La cúpulas, las escaleras de honor y las galerías de la Cámara de la planta principal se ejecutaron con bóvedas catalanas.

\section{Hemiciclos}

El Hemiciclo de la Cámara está construido sobre un muro circular exterior de hormigón armado y pilares intermedios del mismo material. La cubierta de la cámara está sustentada por dieciocho columnas, compuestas por fustes de piedra de Ca- pellanías pulidas y capiteles de bronce fundido, colocadas en forma semicircular y muros de ladrillo reforzados con pilares de hormigón anexos al estrado presidencial. Une estos pilares un arquitrabe de acero sobre el que descansan las columnas, también de acero, que soportan las cerchas. Las esquinas de los palcos presidenciales son de hormigón armado y soportan la cercha principal. De su sección media y perpendicular a ella parte otra cercha que descansa en su otro extremo sobre una viga armada de doble alma. Ocho cerchas radiales secundarias conectadas a la principal se apoyan en su otro extremo en columnas de acero de 10 " $(25,4 \mathrm{~cm})$ que llevan la carga a los arquitrabes en forma poligonal (1).

Para soportar la construcción de las plantas superiores se colocaron 18 vigas de acero de 18 " (45,72 cm) entre el muro exterior y los arquitrabes dispuestas de forma radial (1), correspondiendo con los ejes de las columnas de piedra. La cubierta es de hormigón armado, con un hueco interior de vidrio emplomado decorado (Figura 9). 


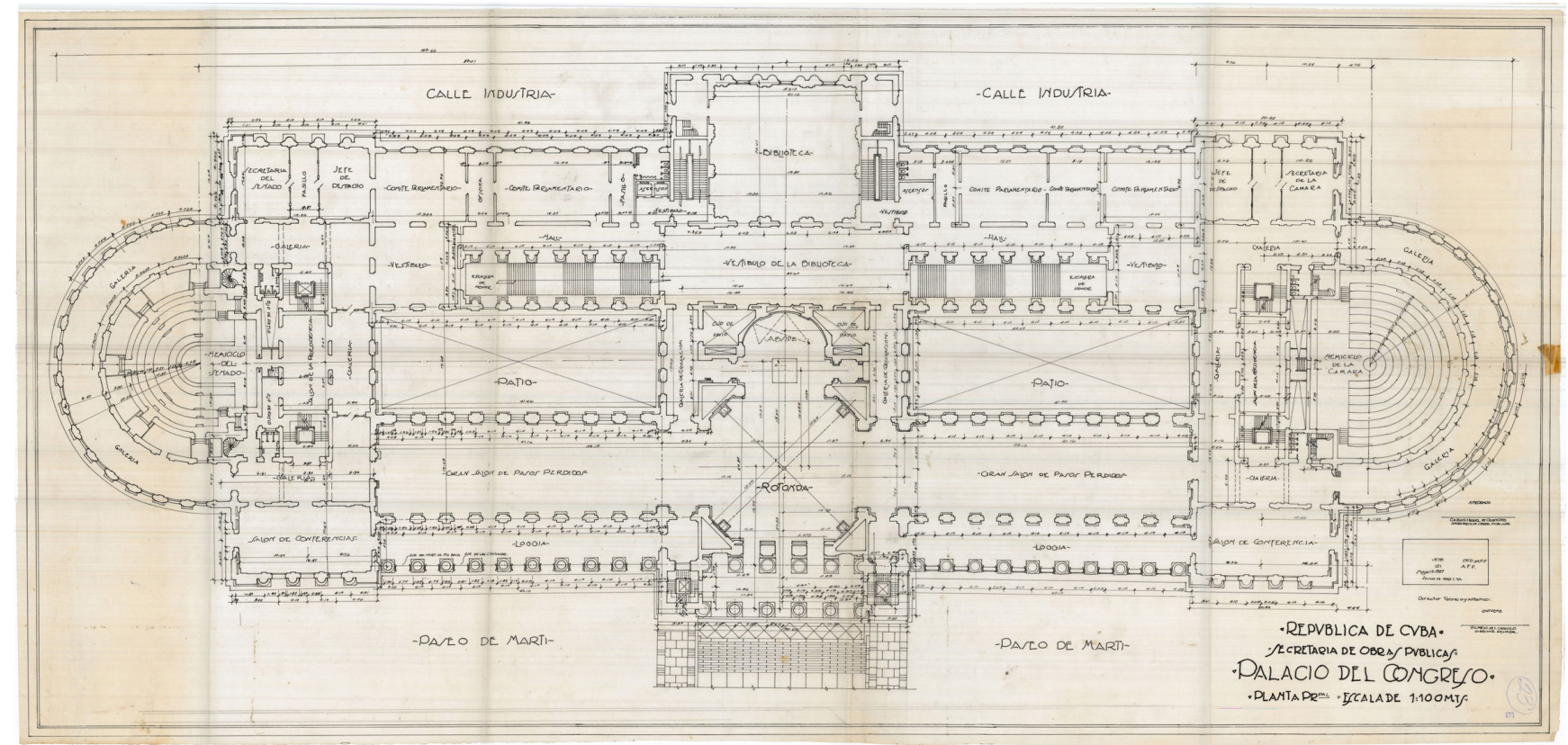

Figura 8. Planta Principal (segunda planta) del Capitolio Nacional de Cuba. 12 mayo 1927. Dibujado por: A.F.P., supervisado por: Hilario del Castillo, Director General.

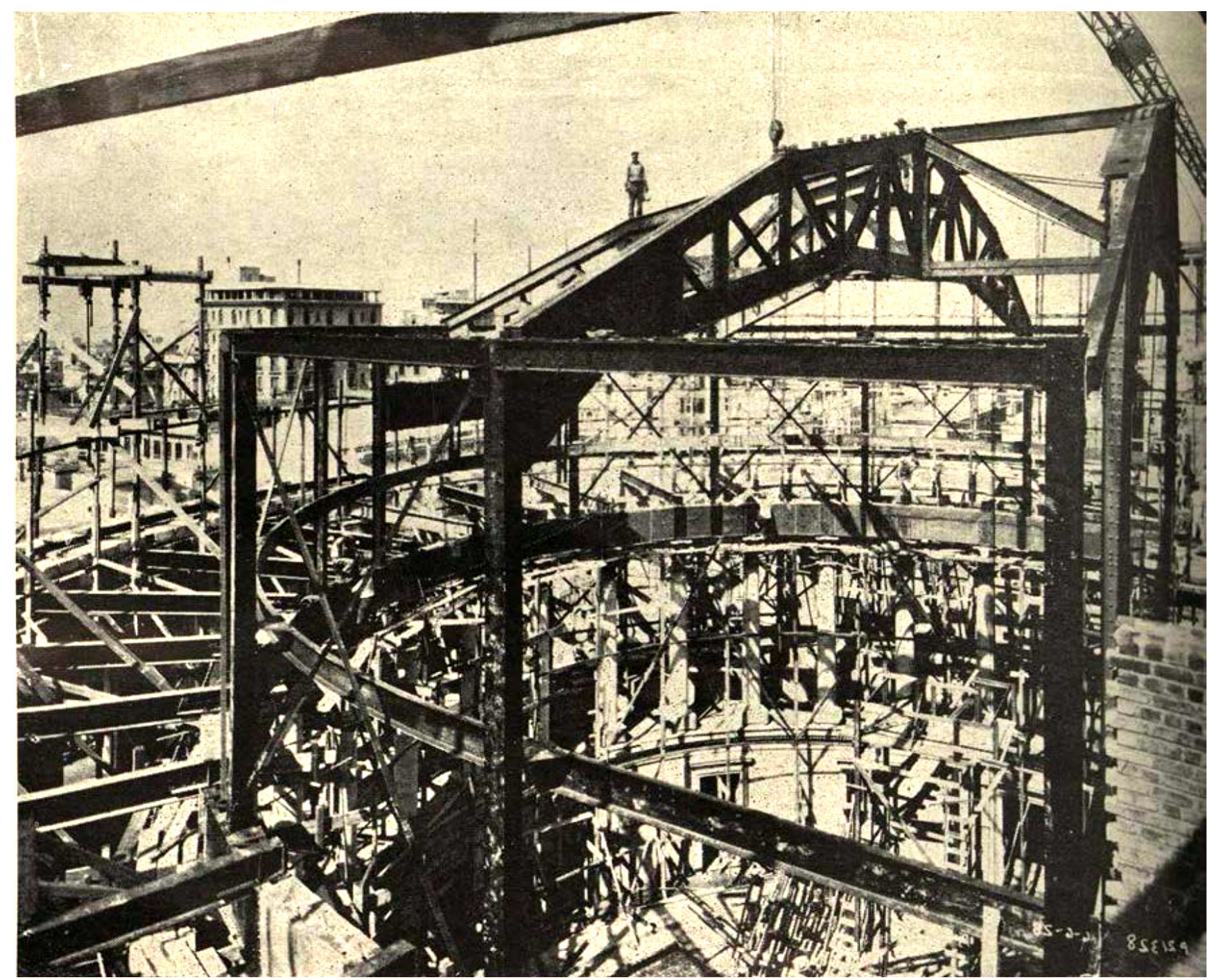

Figura 9. Estructura de acero cubierta Hemiciclo de la Cámara. Fuente: Revista El Arquitecto. Imágenes extraídas del n 38 . "El Capitolio visto por un Arquitecto", publicada en 1933. 


\section{Cúpula}

El diseño y cálculo de la cúpula lo hicieron N. A. Richards y H. V. Spurr, ingenieros de la constructora, en el tiempo récord de una semana para la cimentación y un mes para la estructura.

La cúpula del Capitolio tiene una estructura de acero para aligerar su peso teniendo en cuenta la poca resistencia del terreno y la presencia de arcillas expansivas bajo la cimentación. La estructura apoya sobre cuatro macizos de hormigón que en planta forman un perímetro cuadrado. Sobre cada uno de los macizos arrancan tres pilares de acero. El suelo bajo la cúpula se sitúa en la planta segunda (planta principal), entre el cruce del eje de simetría del edificio y del Salón de los Pasos Perdidos. Para ejecutar el forjado de esta planta con hormigón armado teniendo en cuenta las grandes luces a cubrir $(22,70 \mathrm{~m}$.) y para que el espesor de este fuera el mínimo (6" o 15,24 cm.), se colocaron cuatro vigas arriostrando los macizos de hormigón y otras cuatro vigas apoyadas sobre las anteriores en cada tercio de su longitud. Sobre éstas, a su vez, apoyaban dos nuevas vigas en sus puntos medios sobre las que descansaban finalmente cuatro vigas simples.

El desarrollo estructural de la cúpula se realiza con una estructura doble formada por una subestructura interna con pilares, vigas y cerchas de acero debidamente arriostrados para resistir los vientos tropicales y una exterior que consiste en una cáscara de hormigón revestido.

El tambor presenta ventanas y columnas corintias adosadas por el exterior. En este nivel se emplearon cruces de San Andrés formadas por angulares para soportar los efectos del viento y enlazando las dieciséis columnas interiores con las dos más próximas exteriores. El tambor constituye el basamento del peristilo, desde donde arrancan los nervios del domo para alcanzar, más arriba, la linterna. El peristilo tiene una estructura similar a la del tambor pero con forma circular. Las columnas exteriores son de piedra y las interiores de acero revestidas de hormigón.

\section{CONCLUSIONES}

Desde los inicios de la obra y durante todo su desarrollo, la construcción del Capitolio de La Habana estuvo sometida a continuos desafíos técnicos, que conminaban a los técnicos a adecuar soluciones para aligerar pesos y reducir tiempos.

Aunque los cargos y labores de supervisión de obra y documentación recayeron casi siempre en cargos de la Secretaría de Obras Públicas cubana y en personal delegado por ellos, la influencia de la empresa Purdy and Henderson Co. fue notable. Se encargó de la finalización o modificación de planos durante el transcurso de la obra y su labor fue esencial en los momentos más críticos, como por ejemplo el cálculo de la cimentación y estructura de la cúpula y las alternativas presentadas para aligerar secciones que en los planos aparecían como macizos de hormigón. Para ello se recurrió a profesionales cualificados de la empresa ubicados en sus oficinas de Nueva York a pesar de que el 90\% de sus efectivos eran cubanos.

Aunque la dirección de los trabajos estuviese en Cuba, el hecho de que la constructora fuese extranjera reportó innumerables ventajas a su desarrollo como la agilidad de organiza- ción y comunicación desde sus oficinas neoyorkinas para el pedido y gestión de materiales a cualquier parte del mundo. La maquinaria de construcción y equipos de obra más modernos del momento fueron importados por la empresa para poder solucionar las magnitudes de la obra así como cumplir con los objetivos de fechas y plazos.

Por otra parte, la obra se puede enmarcar dentro del quehacer internacional de la época debido al gran número de participantes e influencias llegadas de Europa como la asunción de la dirección artística por José M. Bens Arrarte que estudió en la Escuela de Bellas Artes de París, adaptando ejemplos de proyectos franceses a las necesidades del edificio, la incorporación de artistas franceses e italianos para el diseño de diversos ornamentos o la contratación de la firma inglesa de decoración de interiores Waring and Gillow que aportó a los trabajos su tecnología y organización. Otro ejemplo fue la contratación de los trabajos en mármol a las firmas Fratelli Remuzzi de Italia y Vereinigte Fichterlgebirge-Granit Syenit o Marmorwerke, A.G. de Alemania.

Su ejecución responde de alguna forma a su momento histórico y cultural: se trata de una obra proyectada con una metodología constructiva decimonónica clásica (mediante el uso estructural de muros de piedra y ladrillo, bóvedas, columnas de piedra, etc.) en la que se introducen algunas mejoras tecnológicas del momento (como los muros y losas de hormigón armado, los pilares, vigas y cerchas de acero) lo que confiere al conjunto un carácter mixto. Además se usó tanto material local (piedra de canteras de la isla y madera de jiquí para pilotes) con tecnología avanzada (aire comprimido para trabajo y labra de piedra) como soluciones importadas de Estados Unidos.

En diversas ocasiones los directores fueron consultados para variar las soluciones constructivas de modo que las secciones resistentes (que como en el caso de la cubierta de la 'Porte Cochera' aparecían totalmente macizas) fuesen menores y el material visto actuase solo como acabado final, a lo que no accedieron, con lo que se puede hablar relativamente de cierta 'verdad constructiva' en el uso de los materiales y su funcionamiento en obra. Se intentó respetar en la medida de lo posible que la colocación de la piedra estuviese en relación a su asiento natural, a la carga que deberían soportar y a la composición de las juntas. En algunas ocasiones se emplearon espesores de piedra superiores a los que ya estaban siendo empleados en Estados Unidos en aquella época.

El acero se introdujo fundamentalmente para aligerar secciones. La solución de las uniones de acero con el resto de obra gruesa se hizo coherentemente con la distribución de cargas, para el correcto funcionamiento estructural de todo el conjunto como fue el caso del diseño de apoyo de cerchas para evitar empujes laterales en la cubierta del Salón de Pasos Perdidos.

Como ha quedado de manifiesto, la conjunción de factores como la organización de operarios y recepción de materiales en la ejecución, el empleo de tecnología importada, el personal cualificado y las empresas extranjeras permitieron llevar a buen término uno de los edificios más emblemáticos de la capital cubana de grandes dimensiones en un tiempo relativamente muy corto y cubriendo la calidad en los detalles que su representatividad requería. 


\section{REFERENCIAS}

(1) Fernández, P. y Cía. (1933) El Libro del Capitolio. La Habana.

(2) Chateloin Santiesteban, F. (2007) De la arquitectura del molde o la identidad de la ciudad cubana. TROCADERO (19): 251-264. https://doi.org/10.25267/Trocadero.2007.i19.16

(3) Mestre Martí, M.; Jiménez Delgado, A.; Ródenas López, M.A.; Jiménez Vicario, P.M. (2018). El Capitolio de La Habana, a través de sus planos originales. EGA Expresión Gráfica Arquitectónica, 23(33): 40-51. https://doi.org/10.4995/ ega.2018.8859

(4) Cuevas Toraya, J. de las, Sala Santos, G., Padrón Valdés, A. (2001). 500 años de construcciones en Cuba. La Habana: Chavín Servicios Gráficos y Editoriales.

(5) El Capitolio visto por un Arquitecto (1933). El Arquitecto, 4(38). La Habana. 